\title{
Alveolar Soft Tissue Sarcoma: A Case Report and Literature Review
}

\author{
A. M. Abdoulwahab ${ }^{1}$, M. Koini ${ }^{2}$, B. S. Souna ${ }^{3}$, \\ A. S. Zirbine ${ }^{3}$, S. K. Akambi ${ }^{4}$, Z. Konguise ${ }^{3}$ \\ ${ }^{1}$ Department of Orthopedics and Traumatology of the Niamey/Niger National Hospital, Niamey, Niger \\ ${ }^{2}$ Department of Orthopedics and Traumatology, Maradi/Niger Regional Hospital, Maradi, Niger \\ ${ }^{3}$ Department of Orthopedics and Traumatology of the Lamordé National Hospital (CHU), Niamey, Niger \\ ${ }^{4}$ Department of Orthopedics and Traumatology of the Zinder/Niger National Hospital, Zinder, Niger \\ Email: *medwahabe@gmail.com
}

How to cite this paper: Abdoulwahab, A.M., Koini, M., Souna, B.S., Zirbine, A.S., Akambi, S.K. and Konguise, Z. (2017) Alveolar Soft Tissue Sarcoma: A Case Report and Literature Review. Open Journal of Orthopedics, 7, 408-413.

https://doi.org/10.4236/ojo.2017.712043

Received: October 15, 2017

Accepted: December 2, 2017

Published: December 5, 2017

Copyright $\odot 2017$ by authors and Scientific Research Publishing Inc. This work is licensed under the Creative Commons Attribution International License (CC BY 4.0).

http://creativecommons.org/licenses/by/4.0/

\begin{abstract}
Soft alveolar sarcoma is a rare tumor $(0.5 \%$ to $1 \%$ of soft-tissue sarcomas) of poor prognosis that often affects the young subject, with a moderate male predominance. The authors present the diagnostic and therapeutic course of a 60 -year-old patient from Niger with no particular previous history, consulted for a painless swelling of the right arm evolving for 6 months, in which the diagnosis of alveolar sarcoma of the soft parts of the arm was selected. A monobloc surgical excision decision was made, with the anatomy and function of the limb retained, with the filling of the area resected with cement and fixed by a locked nail. A conventional three-course chemotherapy regimen was instituted. Alveolar sarcoma of the soft tissues is a rare tumor whose imagery remains unclear, but the diagnosis is based on surgical excision with histopathological examination and immunohistochemical analysis.
\end{abstract}

\section{Keywords}

Alveolar Sarcoma, Soft Tissues, Arms, Support

\section{Introduction}

Alveolar sarcoma of the soft tissues is a rare tumor $(0.5 \%$ to $1 \%$ of the soft-tissue sarcomas) of poor prognosis, which often affects the young subject, with a moderate male predominance [1] [2] (surgeon, radiologist, oncologist, radiotherapist and anatomopathologist), but wide surgical excision remains the best therapeutic option. We report the first case of alveolar soft tissue sarcoma documented in 
Niger.

\section{Clinical Case}

Mr OB patient aged 60 years, native of Niger, without a particular antecedent, consulted for a painless swelling of the right arm evolving for 6 months. On clinical examination, the mass appears very limited, adherent to the skin, without cutaneous retraction, mobile with respect to the deep plane. It measures about $15 \mathrm{~cm}$ long. It is hard and painless, ulcerous-budding, suppurative, fetid odor, without thrill (Figure 1). The rest of the clinical examination is unusual. The standard X-ray of the arm shows only opacity of the soft parts without bone anomaly (Figure 2). The lesion is a hypoechoic tissue, heterogeneous, oval, 16 $\mathrm{cm}$ long, non-fluid, well limited, with regular contours vascularized with color doppler. In MRI, there is a large fleshy, highly vascular mass, as well as skates of diaphyso metaphysary metastases (Figure 3 ). The bacteriological examination of the pus had isolated the germ of Escherichia coli which required antibiotic therapy base of ofloxacin. The extension report performed by thoraco-abdominopelvic CT scan showed micronodules under bilateral pleural lesions that were highly suggestive of secondary lesions (Figure 4), and the remainder of the extensional balance was negative. Bone scintigraphy shows impairment (Figure 5). An ultrasound biopsy with anatomopathological study revealed a clear cell tumor suggestive of soft tissue alveolar sarcoma. A monoblock surgical excision was performed with conservative anatomy and function of the limb with filling of the area resected with cement and fixed by a locked nail (Figure 6), and its pathological analysis confirms the initial hypothesis of alveolar sarcoma of the soft parts done by Lamordé National Hospital (CHU) Niamey/Niger, followed by an immunohistochemical examination which allowed the diagnosis of clear-cell carcinoma of the soft parts of the right arm. A conventional three-course chemotherapy regimen was initiated at this stage of secondary metastasis from the time of initial diagnosis. The clinical course was favorable in the short and medium term with good healing of the wound and absence of secondary local awakening on the right arm (Figure 7).

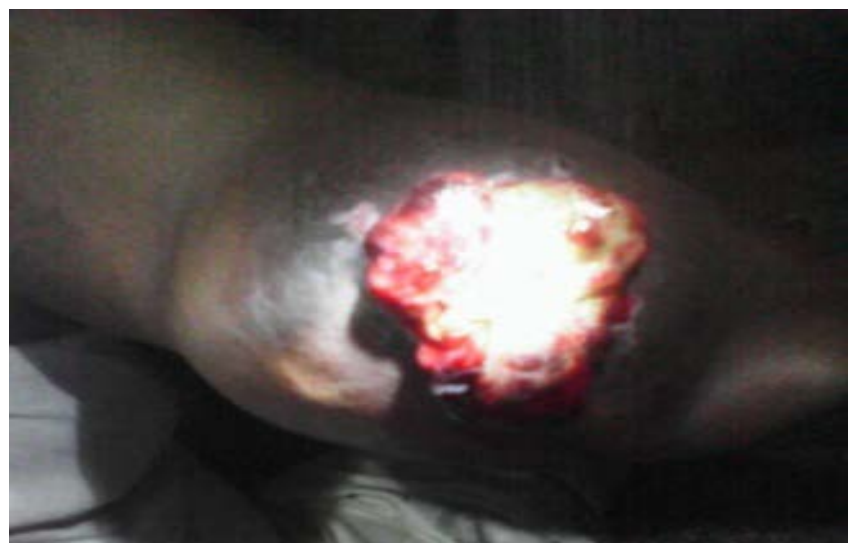

Figure 1. Aspects of the tumor mass on clinical examination. 


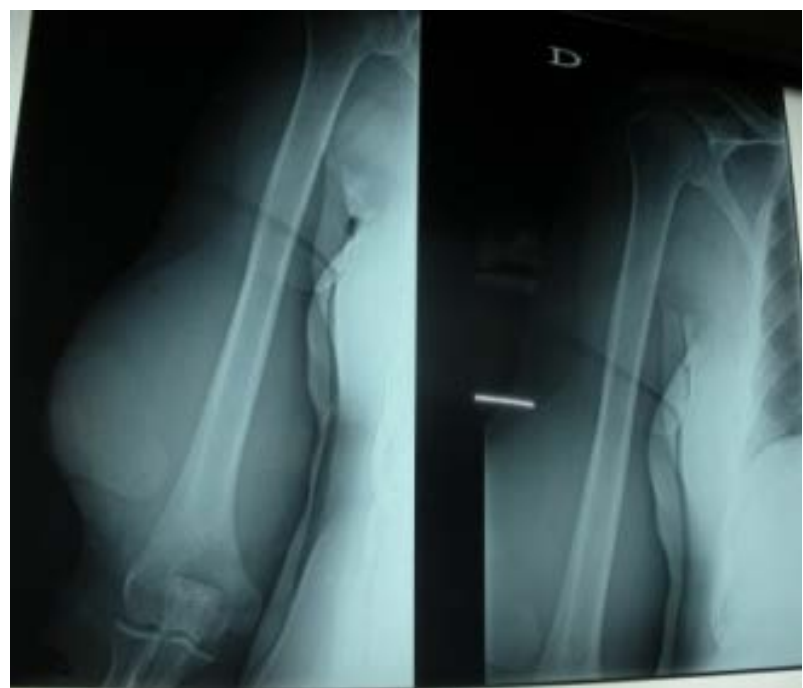

Figure 2. Standard radiography image.

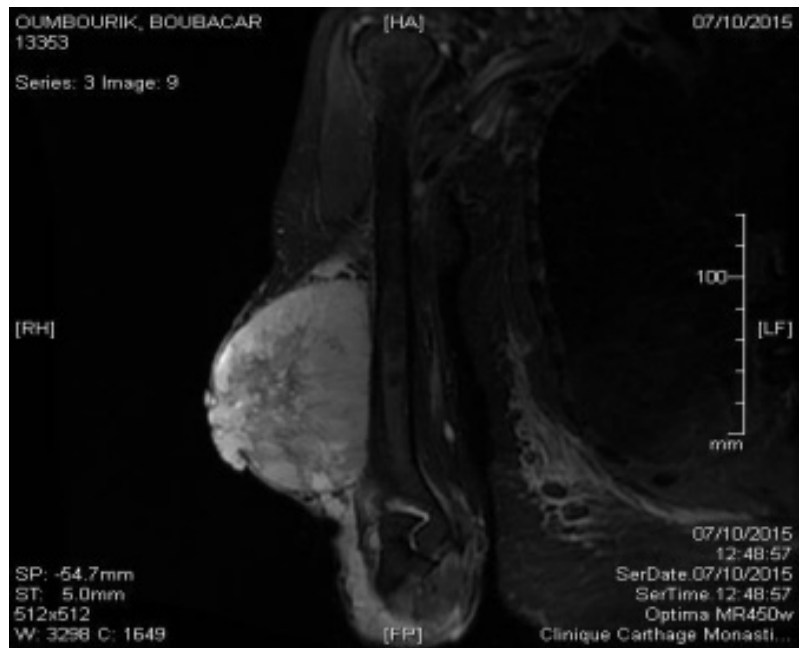

Figure 3. Image of the tumor mass at IRM.

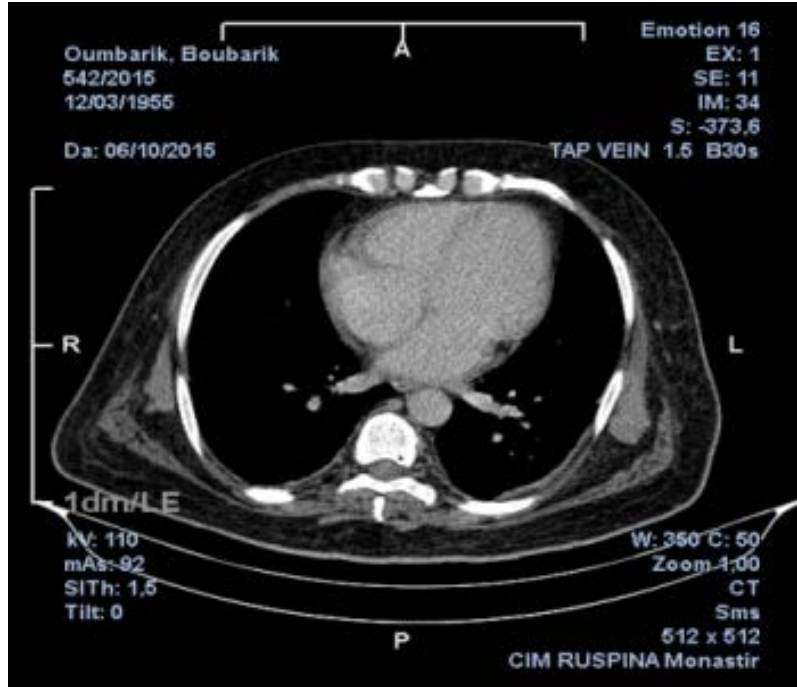

Figure 4. Scannographic image of the tumor extension report. 


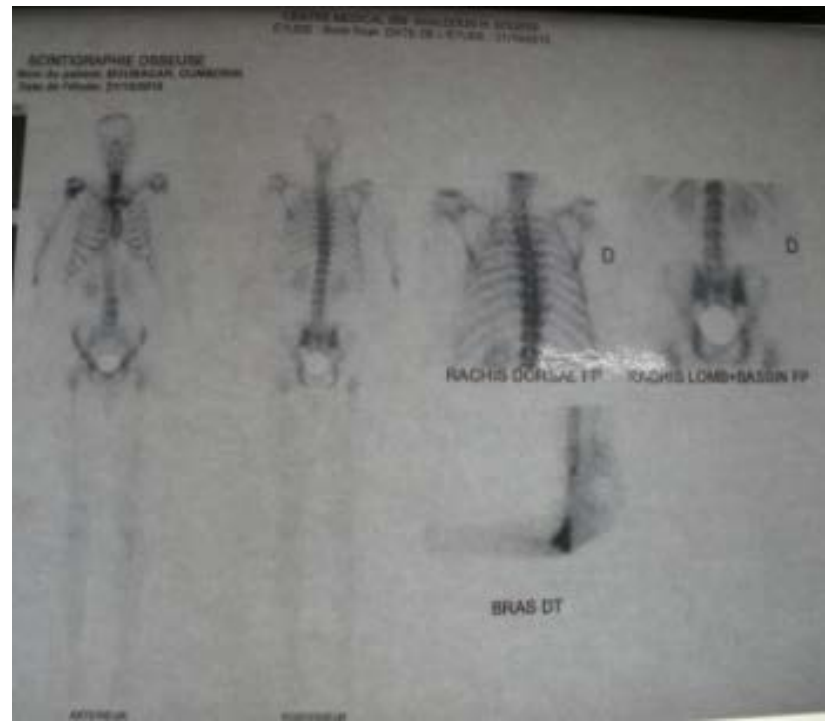

Figure 5. Bone scintigraphy image.

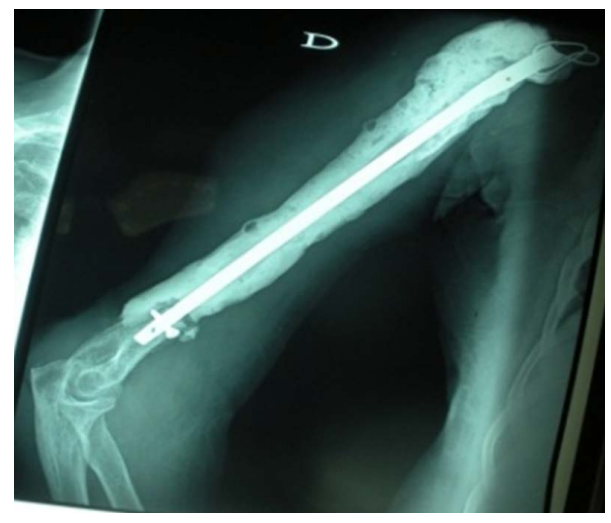

Figure 6. Postoperative control image.

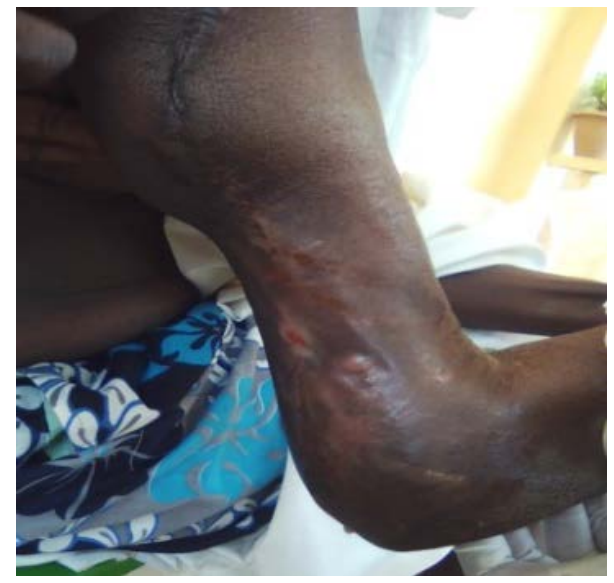

Figure 7. Image of the arm after tumor resection.

\section{Discussion}

Alveolar sarcoma is a rare malignant soft tissue tumor with a dark prognosis. The cost of the first description of alveolar sarcoma of the soft tissue is classically 
attributed to the anatomopathologist Christopherson in 1952. The average age of his diagnosis is around 22 years in women and 27 years in men, but can be seen in children from the age of 2 and also in elderly people [3] [4]. Its preferred site is found in the lower limbs and then in the trunk and upper limbs, in the skeletal muscles in the adult [5] in the great majority of cases, but in children the alveolar sarcoma occurs most often in the region of the head and neck [6]. The prognosis is reserved because of the high incidence of secondary lesions during diagnosis and the low response to chemotherapies [4] [7]. Indeed, given the slow and painless growth of the tumor, the rate of metastases detected at the time of diagnosis is estimated to be about $20 \%$ to $25 \%$ as in our case [4]. Metastases are most frequently found in the lungs, followed by bone and cerebral metastases [7]. The case described in this article presents the characteristics of the alveolar sarcomas of the soft parts. Typically, alveolar sarcoma of the soft tissues is presented in ultrasound as a heterogeneous hypoechoic mass associated with large and numerous blood vessels well demonstrated by the color doppler. The scannographic and magnetic imaging characteristics have been described by Iwamoto et al. in 1995 [5]. From a histological point of view, it has recently been discovered that the genetic study of the translocation of $(17) \mathrm{t}(\mathrm{X} ; 17)(\mathrm{p} 11 ; \mathrm{q} 25)$ and immunohistochemical analysis of the fusion protein ASPL-TFE3 responsible of alveolar sarcoma have eliminated all other diagnosis [8] [9]. Bulk resection is the therapy of choice in the case of localized disease and may require gestures of complex reconstructions (cementation, reinforcement osteosynthesis, free flaps, nerve transplantation, arterial bypass surgery) [10]. Conventional chemotherapy at the time of the initial diagnosis did not significantly improve the survival rate of patients compared to patients who had not received any chemotherapy treatment [11].

\section{Conclusion}

Alveolar sarcoma of the soft tissues is a rare tumor, the imaging of which is not very specific, but the diagnosis is based on surgical excision with histopathological examination and immunohistochemical analysis which have eliminated in recent years any other diagnostic.

\section{Conflict of Interest}

The authors claim that they have no conflict of interest.

\section{References}

[1] Koguchi, Y., Yamaguchi, T., Yamato, M., Osada, D. and Saotome, K. (2005) Alveolar Soft Part Sarcoma of Bone. Journal of Orthopaedic Science, 10, 652-655. https://doi.org/10.1007/s00776-005-0959-8

[2] Pang, L.M., Roebuck, D.J., Griffith, J.F., Kumta, S.M. and Metreweli, C. (2001) Alveolar Soft-Part Sarcoma: A Rare Softtissue Malignancy with Distinctive Clinical and Radiological Features. Pediatric Radiology, 31, 196-199.

https://doi.org/10.1007/s002470000388 
[3] Anderson, M.E., Hornicek, F.J., Gebhardt, M.C., Raskin, K.A. and Mankin, H.J. (2005) Alveolar Soft Part Sarcoma: A Rare and Enigmatic Entity. Clinical Orthopaedics and Related Research, 438, 144-148.

https://doi.org/10.1097/01.blo.0000180049.50832.4a

[4] Lieberman, P.H., Brennan, M.F., Kimmel, M., Erlandson, R.A., Garin-Chesa, P. and Flehinger, B.Y. (1989) Alveolar Soft-Part Sarcoma. A Clinical-Pathologic Study of Half a Century. Cancer, 63, 1-13.

https://doi.org/10.1002/1097-0142(19890101)63:1\%3C1::AID-CNCR2820630102\%3 E3.0.CO;2-E

[5] Aluigi, P., Sangiorgi, L. and Picci, P. (1996) Alveolar Soft Part Sarcoma. Skeletal Radiology, 25, 4002. https://doi.org/10.1007/s002560050104

[6] Charrier, J.B., Esnault, O., Brette, M.D. and Monteil, J.P. (2001) Alveolar Soft-Part Sarcoma of the Cheek. British Journal of Oral and Maxillofacial Surgery, 39, 394-397. https://doi.org/10.1054/bjom.2000.0635

[7] Lieberman, P.H., Foote, F.W.Jr., Stewart, F.W. and Berg, J.W. (1966) Alveolar Soft-Part Sarcoma. JAMA, 198, 1047-1051.

https://doi.org/10.1001/jama.1966.03110230063012

[8] Folpe, A.L. and Deyrup, A.T. (2006) Alveolar Soft-Part Sarcoma: A Review and Update. Journal of Clinical Pathology, 59, 1127-1132. https://doi.org/10.1136/jcp.2005.031120

[9] Christopherson, W.M., Foote, F.W.Jr. and Stewart, F.W. (1952) Alveolar Soft-Part Sarcomas; Structurally Characteristic Tumors of a Certain Histogenesis. Cancer, 5, $100-111$.

https://doi.org/10.1002/1097-0142(195201)5:1\%3C100::AID-CNCR2820050112\%3E 3.0.CO;2-K

[10] Salvati, M., Cervoni, L., Caruso, R., Gagliardi, F.M. and Delfini, R. (1998) Sarcoma Metastatic to the Brain: A Series of 15 Cells. Surgical Neurology, 49, 441-444. https://doi.org/10.1016/S0090-3019(97)00034-7

[11] Portera, C.A.Jr., Ho, V., Patel, S.R., et al. (2001) Alveolar Soft Part Sarcoma: Clinical Course and Patterns of Metastasis in 70 Patients Treated at a Single Institution. Cancer, 91, 585-591. https://doi.org/10.1002/1097-0142(20010201)91:3\%3C585::AID-CNCR1038\%3E3.0. CO;2-0 